\title{
Joint and limb symptoms in children after immunisation with measles, mumps, and rubella vaccine
}

\author{
C M Benjamin, G C Chew, A J Silman
}

\author{
Abstract \\ Objective-To assess whether the combined \\ measles, mumps, and rubella vaccine increases the \\ incidence of joint and limb symptoms in young \\ children.
}

Design-Comparison of six week recalled incidence of symptoms in two groups of children: children who had been immunised at the start of the six weeks, and children eligible for immunisation but who had not received it.

Setting-South Manchester Health Authority.

Subjects -2658 children immunised during July 1989-February 1990 and 2359 not yet immunised. Questionnaires were returned for 1846 immunised children and 1075 not immunised.

Main outcome measure-Recalled rate of joint and limb episodes determined by postal questionnaire and later by clinical follow up.

Results-Compared with non-immunised children the immunised group had an increased incidence of new episodes (relative risk $1.6(95 \%$ confidence interval $(1.2$ to $2 \cdot 1)$ ) and first ever episodes, though this was not significant $(1.7(0.3$ to 3.5$))$. The risk of first episodes was increased in girls $(3 \cdot 5(1 \cdot 1$ to $12 \cdot 2))$ but not in boys $(1.0(0.4$ to 2.6$))$. Similarly, an increased risk was seen in children aged under 5 $(12.0(1.6$ to 92.3$))$ but not in older children $(0.7(0.3$ to 1.5$)$ ). Most episodes were mild and self limiting, but three immunised children required hospital referral.

Conclusion-Measles, mumps, and rubella vaccine is associated with an increased risk of episodes of joint and limb symptoms, especially in girls and children under 5 . The risk of frank arthritis is substantially less than after wild rubella infection.

Arthritis and Rheumatism Council Epidemiology Research Unit, Stopford Building (University of Manchester), Manchester M13 9PT

C M Benjamin, research

fellow

G C Chew, research assistant

A J Silman, director

Correspondence to:

Professor Silman.

BMF 1992;304: 1075-8
In October 1988 the Department of Health introduced a combined measles, mumps, and rubella vaccine to the United Kingdom. This innovatory trivalent vaccine brought rubella immunisation forward to the second year of life and exposed British boys to rubella vaccine for the first time. We present the results from a controlled study in young children from the South Manchester Health District of the incidence of joint and limb complaints occurring within six weeks of immunisation with measles, mumps, and rubella vaccine.

\section{Subjects and methods}

We compared the episode incidence of joint and limb complaints in children (as recalled by the parent) six weeks after exposure to measles, mumps, and rubella vaccine with the recalled episode rate over six weeks in children eligible to receive the vaccine but who were not immunised at the time of the study.

\section{SUBJECTS}

We attempted to identify all children resident in the South Manchester Health District who were notified as having been immunised with measles, mumps, and rubella vaccine during the 30 weeks July 1989 to February 1990. The health authority, after guidance from the Department of Health, ${ }^{10}$ recommended vaccination for all children between the ages of 1 and 5 years. The authority adopted three strategies to ensure vaccine coverage. Firstly, parents of those infants reaching their first birthday were sent an invitation to attend for immunisätion. Secondly, local child health clinics adopted an opportunistic approach in immunising preschool children attending for child surveillance clinics. Finally, children about to enter primary school were also invited to attend for immunisation. A notification by the clinic or general practitioner to the health authority confirming that immunisation had taken place led to entry into the study.

We also obtained comparable data from children not vaccinated but who were eligible to receive immunisation. In an attempt to cover the same age distribution and selection methods as the immunised children, three groups were targeted. Firstly, children approaching their first birthday who were due to be called for immunisation in the next month (infant group); secondly, a clinic group consisting of children who attended a child health clinic for reasons other than immunisation and who were eligible to receive the vaccine, and, thirdly, a school group of children, aged 5 years or more, who were scheduled from the health authority records to receive the vaccine at the school entry medical examination. Thus each of the three groups consisted of children due to be immunised, but we studied the six weeks immediately before entry to the study.

During the study 2658 immunised children and 2359 who were not immunised were contacted - a total of 5017 children. We estimated that the six week episode 
incidence of arthralgia would be about $1 \%$ in nonimmunised children. Assuming a $75 \%$ response rate these population sizes would give the study an $83 \%$ power of detecting, with an $\alpha$ of 0.05 , a doubling in incidence after immunisation.

\section{METHOD OF INVESTIGATION}

In the immunised cohort a screening questionnaire was sent by post to the parents six weeks after the date of immunisation. Non-respondents were sent a second questionnaire, four weeks after the initial one. A similar procedure was adopted for the control cohort, although the exact procedure varied in the three recruitment strategies adopted. Parents of children in the infan group were sent a questionnaire by post on the child's first birthday, timed to arrive before the appointmen postcard for immunisation. The parents of these infants had previously given consent for immunisation. The clinic group were issued with the questionnaire on arriva at the clinic, to be completed and returned immediately. For the school group the questionnaire was included with the consent form posted by health authority staff seeking parental consent to immunisation at the school entry medical.

The questionnaire sought information about health complaints in the preceding six weeks. The accompanying letter described the study as an investigation into the general health of children. Joint and limb complaints were not emphasised. Thus six questions inquired about new episodes of skin rash, fever, swollen glands, coryza, convulsions, or sore eyes. Two questions inquired about consultations with doctors and admissions into hospital These questions were also used to determine whether parents of immunised children reported more adverse health events in general than the parents of the controls. The question that inquired specifically about new episodes of joint or limb complaints was: "In the last six weeks has your child suffered any new episodes of the following problems: (i) swollen joints in the arms or legs? (ii) pain or discomfort in the arms or legs? (iii) pain or discomfort in the hands or feet? and (iv) swollen joints in the hands or feet?"

If parents reported one or more of these four symptoms the child was visited at home, where a full history was taken and the joints examined by a clinician (CMB) with experience in paediatric rheumatology. The home visits were used to validate the parents' recalled answers, to distinguish first ever from other episodes of joint and limb complaints, and where possible to make a clinical diagnosis.

\section{ANALYSIS}

Two outcomes were sought from the screening questionnaire and home visits. Firstly, episodes of joint and limb complaints - that is, discrete events that began in the six weeks immediately before the date of the questionnaire. These included episodes similar or identical to others the child had experienced on one or more occasions in the past. The second outcome was first ever episodes of joint and limb complaints starting in the six weeks before the date of the questionnaire.

Once the episode had been confirmed to be a joint or limb complaint, it was classified into one of four diagnostic categories. Arthralgia was defined as pain experienced in the joint but not accompanied by swelling.

TABLE I-Response rates to posted questionnaires

\begin{tabular}{lccccc}
\hline & & \multicolumn{3}{c}{ Not immunised } \\
\cline { 3 - 5 } & & Infant & \multicolumn{2}{c}{ School } \\
& & Immunised & register & register & Both \\
\hline No of questionnaires issued & 2658 & 871 & 1063 & 1934 \\
No returned after two mailings & 1846 & 536 & 539 & 1075 \\
Crude response rate (\%) & 69 & 62 & 51 & 56 \\
Response rate adjusted for known wrong addresses (\%) & 78 & 69 & 59 & 64 \\
\hline
\end{tabular}

Possible arthritis was defined as swelling of a joint reported by the parent but not corroborated by a doctor. Probable arthritis was defined as swelling of a joint confirmed by a doctor. The final category included the remaining children whose complaints did not fit into one of the above categories and included non-specific limb pains including "growing pains."

The cumulative incidence of all episodes and first ever episodes of joint and limb complaints was calculated for both cohorts. The results are expressed as relative risks with $95 \%$ confidence intervals.

\section{Results}

Table I gives the response rates to the postal questionnaires. The overall response rates, after adjustment for those whose addresses were incorrect, were $78 \%$ in the immunised group and $64 \%$ for the two groups not immunised that received postal questionnaires. A further 425 questionnaires were handed out and returned by the parents attending clinic. Thus altogether we received 1846 questionnaires for immunised and 1500 for nonimmunised children.

TABLE II - Demographic details of eligible children in groups who had and had not received measles, mumps, and rubella vaccine

\begin{tabular}{lccccccc}
\hline & \multicolumn{3}{c}{ Immunised } & & \multicolumn{3}{c}{ Not immunised } \\
\cline { 2 - 3 } \cline { 7 - 8 } Age & $\begin{array}{c}\text { No (\%) } \\
\text { boys }\end{array}$ & $\begin{array}{c}\text { No }(\%) \\
\text { girls }\end{array}$ & Total & & $\begin{array}{c}\text { No(\%) } \\
\text { boys }\end{array}$ & $\begin{array}{c}\text { No (\%) } \\
\text { girls }\end{array}$ & Total \\
\hline$<5$ & $412(52)$ & $391(49)$ & $803(51)$ & & $404(63)$ & $401(67)$ & $805(65)$ \\
$\geqslant 5$ & $382(48)$ & $403(51)$ & $785(49)$ & & $240(37)$ & $197(33)$ & $437(35)$ \\
\hline Total & $794(100)$ & $794(100)$ & $1588(100)$ & $644(100)$ & $598(100)$ & $1242(100)$ \\
\hline
\end{tabular}

These were 258 children who appeared in both the control and the immunised groups. These comprised mainly 1 year old children and clinic attenders aged less than 2 years whose parents completed the questionnaire before immunisation and who completed a further questionnaire six weeks after immunisation was given. None of the parents were aware at the time of completing the first questionnaire that they would receive a subsequent request after immunisation. These children were analysed separately and thus the main analysis compared the 1588 vaccinated children with the 1242 control children. Table II shows the demographic details of these children. The immunised children were older, but the sex distribution between the two groups was similar. The difference in the age distribution reflected the patterns of immunisation and clinic attendance in this population during the study.

TABLE III -Number of children (rate/1000 children) experiencing join syndromes in six weeks before questionnaire completed

\begin{tabular}{|c|c|c|c|}
\hline & $\begin{array}{c}\text { Immunised } \\
(\mathrm{n}=1588)\end{array}$ & $\underset{\substack{\text { Not } \\
(\mathrm{n}=1242)}}{\mathrm{Non}}$ & $\begin{array}{l}\text { Relative risk } \\
\text { (95\% confidence } \\
\text { interval) }\end{array}$ \\
\hline \multicolumn{4}{|l|}{ All episodes: } \\
\hline Arthralgia & $16(10 \cdot 0)$ & $3(2 \cdot 4)$ & $4 \cdot 2(1 \cdot 2$ to $14 \cdot 3)$ \\
\hline $\begin{array}{l}\text { Possible or probable } \\
\text { arthritis }\end{array}$ & $8(5 \cdot 0)-5) \cdot 5 \cdot)$ & $1(0 \cdot 8)$ & $6.3(0.8$ to 50.0$)$ \\
\hline All specific joint syndromes & $24(15 \cdot 1)$ & $4(3 \cdot 2)$ & $4.7(1.6$ to 13.5$)$ \\
\hline \multicolumn{4}{|l|}{ First ever episodes: } \\
\hline Arthralgia & $16(10 \cdot 1)$ & $3(2 \cdot 4)$ & $4 \cdot 2(1.2$ to $14 \cdot 3)$ \\
\hline $\begin{array}{l}\text { Possible or probable } \\
\text { arthritis }\end{array}$ & $7(4 \cdot 4$ & $1(0 \cdot 8)$ & $5.5(0.7$ to 44.4$)$ \\
\hline All specific joint syndromes & $23(14 \cdot 5)$ & $4(3 \cdot 2)$ & $4.5(1.6$ to 13.0$)$ \\
\hline
\end{tabular}

In total, 145 (91/1000 children) of the immunised and $73(59 / 1000)$ of the non-immunised children were reported as having had an episode of joint and limb complaint in the relevant six weeks. The overall risk of all episodes of joint and limb complaints was significantly greater for vaccinated children than for those not vaccinated (relative risk $1 \cdot 6,95 \%$ confidence interval $1 \cdot 2$ to $2 \cdot 1)$. All but 16 of these children were visited at home. 
TABLE IV - Number of children (rate/1000 children) experiencing joint and limb symptoms according to sex and age

\begin{tabular}{|c|c|c|c|c|c|c|}
\hline & \multicolumn{3}{|c|}{ All episodes } & \multicolumn{3}{|c|}{ First ever episodes } \\
\hline & Immunised & $\begin{array}{c}\text { Not } \\
\text { immunised }\end{array}$ & $\begin{array}{c}\text { Relative risk } \\
\text { (95\% confidence } \\
\text { interval) }\end{array}$ & Immunised & $\begin{array}{c}\text { Not } \\
\text { immunised }\end{array}$ & $\begin{array}{c}\text { Relative risk } \\
(95 \% \text { confidence } \\
\text { interval })\end{array}$ \\
\hline Boys & $69(86.9)$ & $41(63 \cdot 7)$ & $1.4(0.9$ to 2.0$)$ & $10(12 \cdot 6)$ & $8(12 \cdot 4)$ & $1.0(0.4$ to 2.6$)$ \\
\hline Girls & $76(95 \cdot 7)$ & $32(53 \cdot 5)$ & $1.8(1.2$ to 2.7$)$ & $14(17 \cdot 6)$ & $3(5 \cdot 0)$ & $3.5(1 \cdot 1$ to $12 \cdot 2)$ \\
\hline$<5$ years & $54(67 \cdot 2)$ & $23(28 \cdot 6)$ & $2.4(1.5$ to 3.8$)$ & $12(14 \cdot 9)$ & $1(1 \cdot 2)$ & $12 \cdot 0(1 \cdot 6$ to $92 \cdot 3)$ \\
\hline$\geqslant 5$ years & $91(115.9)$ & $52(119 \cdot 0)$ & $1.0(0.7$ to 1.3$)$ & $12(15 \cdot 2)$ & $10(22 \cdot 9)$ & $0.7(0.3$ to 1.5$)$ \\
\hline
\end{tabular}

Most of these episodes were non-specific limb pains not affecting the joints, and only 28 children ( 24 immunised, 4 non-immunised) had pain or swelling of the joints (table III).

Restricting analysis to first ever episodes, there were $24(15 / 1000)$ in the immunised group and $11(9 / 1000)$ in the non-immunised group (relative risk $1 \cdot 7,95 \%$ confidence interval 0.8 to $3 \cdot 5$ ). Apart from one child with pre-existing diagnosed arthritis all the episodes of arthralgia or arthritis that were reported during this study were first ever episodes (table III) and the relative risks remained virtually unchanged. Three children had joint swelling confirmed by a doctor (probable arthritis) and all had been immunised.

The results were then analysed separately after stratification by age and sex. Girls were at similar risk to boys for all episodes of joint and limb complaints, but those aged under 5 years had a greater risk (relative risk 3.4) than older children (table IV). Restricting the analysis to first ever episodes, however, suggested that the increased risk was confined to girls and particularly to those under 5 years.

The incidences of new episodes of sore eyes, convulsions, coryza, swollen glands, fever, and skin rash were not significantly different between the immunised and non-immunised groups. Consultations with doctors and admissions to hospital were, if anything, more common among the controls (table V).

TABLE $\mathrm{v}-N$ umber of children (rate/1000 children) experiencing ill health in six weeks before completion of questionnaire

\begin{tabular}{lccc}
\hline Event or symptom & $\begin{array}{c}\text { Immunised } \\
(\mathrm{n}=1588)\end{array}$ & $\begin{array}{c}\text { Not } \\
\text { immunised } \\
(\mathrm{n}=1242)\end{array}$ & $\begin{array}{c}\text { Relative risk } \\
(95 \% \text { confidence } \\
\text { interval })\end{array}$ \\
\hline Hospital admission & $76(48)$ & $78(63)$ & $0 \cdot 8(0 \cdot 6$ to $1 \cdot 1)$ \\
Doctor consultation & $616(388)$ & $554(446)$ & $0 \cdot 9(0 \cdot 8$ to $1 \cdot 0)$ \\
Sore eyes & $154(97)$ & $150(121)$ & $0 \cdot 8(0 \cdot 6$ to $1 \cdot 0)$ \\
Convulsion & $11(7)$ & $5(3)$ & $1 \cdot 6(0 \cdot 6$ to $4 \cdot 6)$ \\
Coryza & $897(565)$ & $797(642)$ & $0.9(0 \cdot 8$ to $1 \cdot 0)$ \\
Swollen glands & $184(116)$ & $135(109)$ & $1 \cdot 1(0 \cdot 8$ to $1 \cdot 3)$ \\
Fever & $279(176)$ & $262(211)$ & $0 \cdot 8(0 \cdot 7$ to $1 \cdot 0)$ \\
Skin rash & $260(164)$ & $216(174)$ & $0 \cdot 9(0 \cdot 8$ to $1 \cdot 2)$ \\
& & &
\end{tabular}

Of the children who experienced first ever episodes, three (all boys), developed probable arthritis in the six weeks after immunisation. Two of these boys were admitted to hospital with arthritis of the hip. Both completely recovered. One boy developed a swollen left ankle and remained under the care of a rheumatologist.

In the 258 children for whom data were available both before and after immunisation there were two episodes of joint and limb complaints in the six weeks before immunisation compared with 10 in the six weeks after immunisation (relative risk $5 \cdot 0,95 \%$ confidence interval $1 \cdot 1$ to $22 \cdot 1$ ). None of these children experienced a first ever episode of joint or limb complaint in the six weeks preceding or following immunisation.

\section{Discussion}

We found that exposure to measles, mumps, and rubella vaccine was associated with an increased risk of developing joint and limb complaints in the six weeks after immunisation. The increased risk for all episodes was not large and the confidence intervals were wide.
The increase in risk was greater when only arthralgia or arthritis were considered. Fortunately, most episodes were short lived and resolved spontaneously and were of little consequence. Children under 5 years were most at risk, and girls had a higher rate of first ever episodes than boys. However, morbidity was perhaps more severe among the boys, as shown by the three boys who had probable arthritis diagnosed. It is important to consider the possible sources of bias.

POSSIBLE BIASES

Selection bias-The immunised cohort included all children from the target population immunised in the study period whereas the non-immunised cohort was essentially chosen from two sources: the same register as used for the immunised children and a group who had opportunistically attended local community child health clinics. This second group had attended clinic for various reasons and children were eligible for inclusion in this study as they had not yet been vaccinated. These attenders may have been selectively less likely to have had joint complaints in previous six weeks. Several points suggest that this potential source of bias is unlikely. Firstly, the differences between the groups persisted after excluding these children. Secondly, there were no differences in the recalled episode rate of other symptoms in this group compared with the immunised group.

Non-response bias-There was a higher non-response rate in the non-immunised group receiving a postal questionnaire (table II) and responders in this group may have been selectively less likely to recall joint and limb symptoms. This seems intuitively unlikely. There was also no difference in rates of symptom recall between those who responded to the first and to the second mailings. Furthermore, the failure to find a difference in the recalled rate of other symptoms would argue against this potential source of error.

Recall bias-The subjects contacted were unaware of the hypothesis and the questions about joint symptoms were included in a list of other complaints. The parents of the clinic children were given their questionnaire in the clinic, which was obviously a different setting from that of parents receiving a postal questionnaire. We cannot exclude the possibility that the postal approach was more likely to result in recall of joint and limb symptoms, but for the reasons mentioned in relation to selection bias this seems unlikely.

Observer bias-The observer undertaking the home assessments was not blind to the immunisation status of the child, and this could have introduced bias in the diagnosis of episodes of joint and limb complaints. The relative risks were indeed higher for the observer assessed arthralgia or arthritis subgroup than for the parents' o reports of all episodes. A standardised evaluation was undertaken and the classification criteria used (see methods) were designed to reduce observer error.

\section{CAUSE OF JOINT SYMPTOMS}

Arthralgia and arthritis have not been described after infection with wild measles virus or after immunisation with measles vaccine. A few isolated case reports exist of arthritis after infection with wild mumps $T$ virus, but there are no cases described after mumps immunisation. ${ }^{11}$ The numerous reports of arthritis complicating infection with wild rubella virus and $\stackrel{\mathbb{D}}{\varnothing}$ immunisation with rubella vaccine make this com- 0 ponent of the vaccine most likely to have caused the joint symptoms reported. The risks of arthritis after wild rubella infection are far greater than those found after vaccination in this study. In one report of young females over $50 \%$ developed acute polyarthritis. ${ }^{4} \mathrm{~A}$ recent British study of measles, mumps, and rubella vaccine found no cases of arthritis among 12023 immunised children, based on a diary of symptoms 
kept by their parents for 21 days after immunisation. ${ }^{12}$ These results need to be interpreted with some caution. Firstly, data were analysed for only 7831 children $(65 \%$ of the cohort) and, more importantly, specific questions relating to joint symptoms were not asked of the parents. Furthermore, joint symptoms may develop later than 21 days after immunisation..$^{48}$

The introduction of universal measles, mumps, and rubella immunisation of young children has implications for child morbidity and public health. Although joint and limb complaints were not uncommon, in most instances morbidity was slight and the episodes self limiting. Coryza, fever, skin rash, swollen glands, and sore eyes were common background events among both immunised and non-immunised children. Many children consulted their doctors, and some were admitted to hospital, mostly for reasons unrelated to the vaccine. Nevertheless, immunisation with measles, mumps, and rubella vaccine carries a risk of first ever episodes of joint symptoms, particularly in children under 5 years and in girls. The most severe cases of arthritis were interestingly seen in older boys. This is of some reassurance given that current policy will result in most children in the United Kingdom being immunised at about 12 months of age.

The study was funded by a grant from the North West
Regional Health Authority. CMB was an Arthritis and Rheumatism Council training fellow in epidemiology. We thank the staff at the North West Regional Health Authority computing centre for providing the data which allowed the selection of the children for the study; the community child health staff from the South Manchester Health District for their support and cooperation in surveying the child health clinics; and Dr Deborah Symmons for her comments on the manuscript.

Loudon ISL. Polyarthritis in rubella. BMJ 1953;i: 1388

2 Fry J, Dillane JB, Fry L. Rubella 1962. BMJ 1962;ii:833-4

3 Hilderbrandt HM, Maassab HF. Rubella synovitis in a one year old patient. N Engl f Med 1966;274:1428-30.

4 Tingle AJ, Allen M, Petty RE, Kettyls GD, Chantler JK. Rubella-associated arthritis. 1. Comparative study of joint manifestations associated with natural rubella infection and RA 27/3 rubella immunisation. Ann Rheum Dis 1986;45:110-4.

5 Spruance SL, Smith CB. Joint complications associated with derivatives of HPV-77 rubella virus vaccine. Am 7 Dis Child 1971:122:105-11.

6 International conference on rubella immunisation. Am 7 Dis Child 1969;118: $1+40$.

7 Preblud SR. Some current issues relating to rubella vaccine. $7 A M A$ 1985;254: 253-6.

8 Balfour HH, Balfour CL, Edelman CK, Rierson PA. Evaluation of Wistar RA 27/3 rubella virus vaccine in children. Am 7 Dis Child 1976;130:1089-91. 9 Peltola H, Heinonen OP. Frequency of true adverse reactions to measlesmumps-rubella vaccine. Lancet 1986; ; $939-42$

10 Joint Committee on Vaccination and Immunisation. Immunisation against infectious disease. London: HMSO, 1990

11 Lass R, Shephard E. Mumps arthritis. BMf 1961;ii: 1613-4.

12 Miller C, Miller E, Rowe K, Bowie C, Judd M, Walker D. Surveillance of symptoms following MMR vaccine in children. Practitioner 1989;233:69-73.

(Accepted 24 February 1992)

\title{
Life events and breast cancer prognosis
}

\author{
Jennifer Barraclough, Pamela Pinder, Marie Cruddas, Clive Osmond, Irving Taylor, Michael Perry
}

University Department of Psychiatry, Royal South Hants Hospital,

Southampton SO9 4PE Jennifer Barraclough, senior research fellow

Pamela Pinder, research assistant

\section{MRC Environmental} Epidemiology Unit, Southampton General Hospital, Southampton SO9 4XY

Marie Cruddas, statistician Clive Osmond, statistician

University Surgical Unit, Royal South Hants

Hospital, Southampton SO9 4PE

Irving Taylor professor of surgery

Queen Alexandra Hospital, Portsmouth PO6 3LY Michael Perry, consultant surgeon

Correspondence to: $\mathrm{Dr}$ Jennifer Barraclough, Sir Michael Sobell House, Churchill Hospital, Oxford OX3 7LJ.

\section{Abstract}

Objective-To determine whether psychosocial stress, in the form of adverse life events and social difficulties, depressive illness, or lack of confiding relationships, shortens the postoperative disease free interval in breast cancer patients.

Design-Prospective follow up of a cohort of newly diagnosed breast cancer patients for $\mathbf{4 2}$ months after primary surgical treatment, using a life events and social difficulties schedule (LEDS) and assessment of depressive symptomatology (DSM-III).

Setting-Patients recruited from breast clinics in Southampton and Portsmouth were interviewed in their homes.

Patients -204 women ( $83 \%$ of 246 consecutive cases) treated either by mastectomy or wide excision followed by radiotherapy interviewed four, 24 , and 42 months after operation.

Main outcome measures-Hazard ratios for relapse of breast cancer in relation to various measures of psychosocial stress. Relapse was defined as local recurrence or distant metastasis, or both, with histological or radiological confirmation and timed from the month when clinical symptoms began.

Results-After adjustment for age and axillary lymph node involvement, the hazard ratio associated with severe life events or social difficulties (excluding "own health" ones), or both, during the year before breast cancer surgery was 0.43 (95\% confidence interval 0.20 to 0.93 ); for those during the follow up period it was $0.88(0.48$ to 1.64$)$. For prolonged major depression before surgery and during the follow up period, hazard ratios were $1.26(0.49$ to 3.26$)$ and $0.85(0.41$ to 1.79$)$ respectively. For absence of a full confidant the figures were $0.93(0.42$ to 2.09$)$ and 0.86 $(0.38$ to 1.93$)$.

Conclusion-These results give no support to the theory that psychosocial stress contributes to relapse of breast cancer.

\section{Introduction}

Whether emotional stress affects the course of cancer is a question of relevance to scientists and clinicians, of concern to patients and their families, and of interest to the general public. Laboratory studies, mostly using animal tumour models, have shown immunological and hormonal pathways through which stress might alter host resistance, but the relevance of these findings to the clinical course of human cancer is not known. One recent review of clinical research in the field concludes: "Most studies that have controlled for the biological contribution have found the magnitude of psychosocial influences to be small."'

Despite the lack of evidence, belief in a causal stresscancer link seems to be widespread, forming a rationale for many modern complementary therapies and media presentations and having implications for clinical practice. If psychosocial factors affect prognosis then cancer treatment programmes should include more psychosocial care. If they do not, patients could be spared the burden of wondering if their own or other people's behaviour is to blame for progression of their disease.

We carried out a prospective interview study to test the main hypothesis that experience of adverse life events shortens the disease free interval following treatment for operable breast cancer. This approach was chosen for three reasons. Firstly, studying the prognosis, as opposed to the onset, of cancer permits the use of a prospective design with more precise timing of variables. Secondly, life events such as bereavement or divorce represent one aspect of "stress" that can be measured with feasonable accuracy. Thirdly, breast cancer is a common disease and attracts 